\title{
DIGIEYE APPLICATION IN COTTON COLOUR MEASUREMENT
}

\author{
Małgorzata Matusiak \\ Lodz University of Technology, Institute of Textile Architecture, 116 Zeromski Str., 90-924 Lodz, Poland \\ e-mail: malgorzata.matusiak@p.lodz.pl
}

\begin{abstract}
:
Colour is one of the most important properties of cotton raw materials. It helps in determining and classifying the quality of fibres according to the Universal Cotton Standards. Organoleptic and instrumental techniques are applied to assess the color of cotton. Worldwide, the colour parameters of cotton are measured by the High Volume Instrument (HVI), which provides information on reflectance $(R d)$ and yellowness $(+b)$ that is specific for cotton, but are not the typical and globally recognized colour characteristics. Usually, worldwide, the colour of textile products and other goods is assessed utilizing the spectrophotometer, which provides the colour data that is widely recognized and accepted by the CIE $L^{*} a^{*} b^{*}$ colour space. This paper discusses utilizing the DigiEye system to measure the colour parameters of cotton samples and compares the results with the colour parameters from the HVI.
\end{abstract}

\section{Keywords:}

Cotton, colour, reflectance, yellowness, High Volume Instrument, DigiEye

\section{Introduction}

Cotton is a basic textile raw material of natural plant origin. Because of its natural origin, the properties of cotton fibres vary significantly, depending on the region of cultivation, variety and growing conditions.. Factors connected with cotton cultivation, such as soil, irrigation, climatic conditions, insects and fungi, way of harvesting significantly influence the basic properties of cotton fibres, that is, maturity, length, fineness, tenacity and colour [10]. The precise measurement of particular cotton properties is necessary to assess the quality of cotton as well as to predict the behaviour of cotton fibres during processing and the quality of the manufactured cotton products (e.g. yarns and fabrics) [9].

Colour is one of the most important properties of cotton. Apart from the factors mentioned earlier, the colour of cotton can be affected by: staining through contact with the soil, grass, etc., as well as by conditions of cotton storage (e.g. moisture and temperature) $[7,19]$. That being so, the deterioration in colour indicates the lower processing efficiency and, at the same time, lowers market value of cotton. A worsening of color also affects the ability of fibres to absorb and hold dyes and finishes [2].

Colour is a basic criterion that determines the quality classification of cotton raw materials according to the Universal Cotton Standards, which is globally accepted and routinely used in many countries as the standard for US and non-US grown cottons $[4,8,16,20,21]$.

\section{Methods of cotton colour measurement}

Traditionally, the assessment of cotton colour has been performed organoleptically, that is, by a visual comparison of the cotton sample to be assessed with a set of the physical standards under standard illumination. It is done by the specially trained cotton classers. The practice of measuring the cotton colour by means of instruments started in the US in the 1930's [11]. The cotton colour is determined instrumentally by a two-filter colorimeter that provides two colour parameters of reflectance $(R d)$ and yellowness $(+b)$. The $\mathrm{Rd}$ indicates how bright or dull a sample is and the $+b$ indicates the degree of colour pigmentation. The colorimeter technology has been integrated into the high volume instrument ( $\mathrm{HVI})$ [11]. It is an automatic measurement system for evaluating cotton based on complex set of parametes. It measures the fibre length, length uniformity, breaking strength, breaking elongation of fibre bundle, micronaire, colour and contamination. For measuring the colour, the HVI utilizes a dual Xenon light source to illuminate a sample window measuring $2.8 \times 3.6$ in. to give a colour sample area measuring $10.1 \mathrm{sq}$. in $[12,18]$. The HVI measures the two colour parameters of $\mathrm{Rd}$ and $+b$. The $\mathrm{Rd}$, as determined by the $\mathrm{HVI}$, expresses the whiteness of the light that is reflected by the cotton fibres, whereas the $+b$ expresses the yellowness of the reflected light.

The colour of cotton can also be measured by other instruments, such as the FQT/FibroLab (Lintronics) and the IsoTester (Schaffner Technologies, Inc.) [9]. The FQT/FibroLab is a multifunctional testing system for cotton. In fact, it also acts as a simulator for some of the spinning processes. A sample is entered into a self-cleaning micro-carding device, which has been integrated with the FQT, to produce a transparent web in order to expose the impurities and contaminants. The web is then recollected in a $10 \times 10 \mathrm{~cm}$ chamber equipped with a window and a colour detecting camera for testing the colour [14]. 
The IsoTester employs a digital colour scanning technique to determine the colour of the cotton samples. The image-based colour data are derived from a large digital colour image of sample. The test area is $28 \mathrm{sq}$. in. [17]. In addition to the large area of measurement, an additional advantage of the IsoTester is the elimination of trash influence on colour results, because the colour measurement is done for the lint-only area of sample [11]. The IsoTester provides the colour parameters of the $\mathrm{Rd}$ and $+b$.

There are also some attempts to measure colour of cotton by means of spectrophotometer [13, 15, 17]. A spectrophotometer measures the amount of light that a sample absorbs. The instrument operates by passing a beam of light through a sample and measuring the intensity of light reaching a detector [12]. Spectrophotometer provides the colour data in $\mathrm{CIE}$ (Commission Internationale de l'eclairage) $\mathrm{L}^{*} \mathrm{a}^{*} \mathrm{~b}^{*}$ colour space. It is the most popular, standardized colour space. It is a mathematical transformation of the CIE XYZ colour space. By means of the spectrophotometer, the following colour coordinates can be determined:

$$
L^{*} \text { - lightness, }
$$

chromaticity coordinates:

$$
a^{*} \text { - green/red, }
$$

$b^{*}$ - blue/yellow,

$\mathrm{C}^{*}$ - chroma; it is an attribute of colour that is used to indicate the degree of departure of the colour from a grey of the same lightness [5],

$\mathrm{h}$-hue angle; it is an attribute of visual perception according to which an area appears to be similar to one of the colours, red, green, yellow and blue, or to a combination of adjacent pairs of these colours considered in a closed ring [5].

Investigation [13] has confirmed that there exists a statistically significant correlation between the results of cotton colour measurement from the $\mathrm{HVI}$ and spectrophotometer, especially between the lightness from the spectrophotometer and $\mathrm{Rd}$ from the HVI. However, applying of the spectrophotometer for cotton colour measurement and cotton classification is still in the experimental phase.

Scientists dealing with cotton are making efforts to find an instrumental method of the cotton colour measurement to serve an alternative to the HVI. It seems to be justified, because cotton colour measurement by means of the HVI is not without problems. It does not measure cotton semiproducts and colour of the naturally coloured cotton. Colour parameters from the $\mathrm{HVI}$, that is the $\mathrm{Rd}$ and $+b$, are specific to cotton, but they are not the typical and globally recognized colour characteristics. Cotton contamination also affecs the results from the HVI.

\section{Experimental}

The aim of this paper is to present a new method to measure the colour of cotton fibres, that is the DigiEye system, as well as to assess conformity of the results from the DigiEye with results from the $\mathrm{HVI}$.

\subsection{Material and method}

The measurement of colour was performed for 21 cotton samples. They were randomly chosen cotton raw materials of different origin, such as Turkey, Mali, Uzbekistan, India, Greece, Syria and Bulgaria. First, five cotton samples were measured in order to establish the way of choice of the image area for measurement by means of the DigiEye. Next, of the 21 samples, 5 samples were measured in first part of investigation and 16 new cotton samples were measured using the established way of choice of sample image area for the colour measurement.

Measurement of colour of the investigated cotton samples were carried out by means of the DigiEye and HVI 900.

The DigiEye is a computer-controlled digital camera system for measuring colour and capturing high-quality repeatable images. With the DigiEye system, it is possible to capture colorimetrically accurate images of 2- and 3D samples and save the images in the digital files. DigiEye provides $\mathrm{Rd}$ and colorimetric data from samples with an ultra-small area, irregular or curved surfaces $[1,3,6]$. First, an image is captured by the calibrated digital camera; the colour measurement of the object image is then performed by the DigiEye software.

Values of colour parameters from the image of the investigated object are derived under a particular light source. The measurement data are reported in terms of colorimetric values ( $X Y Z$ and $C I E L^{*} a^{*} b^{*}$ ) and spectral reflectance $R$, ranging from $400 \mathrm{~nm}$ to $700 \mathrm{~nm}$ at $10 \mathrm{~nm}$ interval.

The DigiEye provided complex colour data for each selected area and average value for investigated sample as an arithmetic mean from values determined for particular selected areas. Colorimetric values $\mathrm{X}, \mathrm{Y}, \mathrm{Z}$ with $\mathrm{L}^{*}, \mathrm{a}^{*}, \mathrm{~b}^{*}$ are recorded against a selection of standard illuminants. The illuminants are D65, D50, A, F2, F7 and F11. Illuminant D65 belongs to the series of $D$ illuminants representing the natural day light. Illuminant D65 is an average CIE daylight with a correlated colour temperature of $6500 \mathrm{~K}$; whereas the illuminant D50 is an average CIE daylight with a correlated temperature of $5000 \mathrm{~K}[3,22]$. Illuminant $A$ represents an incandescent or tungsten light source and is equivalent to a black body with the colour temperature of $2856 \mathrm{~K}$ [3, 22]. A series of illuminants $\mathrm{F}$ represents typical spectral power distribution (SPD) with a range of fluorescent sources. F2 reflects the fluorescent light with a correlated colour temperature of $4230 \mathrm{~K}$.

Until now, the DigiEye has not been applied for cotton colour measurement. The preliminary procedure to measure colour has been prepared. This procedure assumes that the colour measurement should be done for raw cotton samples in a way that is similar to samples subjected to the organoleptic visual assessment and HVI measurement. Samples of loose cotton fibres of mass ca. $100 \mathrm{~g}$ were taken from the cotton bale and put into the DigiEye cabinet (Figure 3). The cabinet was lighted by a combination of fluorescent D65 illuminant and additive LEDs to allow the production of calibrated A-rated D65 simulator. Next, a picture of the sample was captured by the calibrated Nikon D series digital camera. 
Using the DigiPix option, the colour was measured for the selected area of the investigated sample. In first part of the investigation for each cotton sample, the colour measurement was performed twice:

- in the first step, a selection of the measured area was done with the Rectangle Tool - five rectangular areas of similar dimensions were chosen (Figure 1) and then an arithmetic mean from five measured values of particular colour parameters were calculated as a final result.

- in the second step, the Free-Form Tool was applied to choose an area of colour measurement. In this case, a big area was selected that covered a majority of measured sample area (Figure 2).

While choosing the area for colour measurement, it was assumed that areas with big spaces between fibres or fibre boundles should be avoided. The 3D objects of irregular shape and irregular arrangement of fibres were measured. In some samples, there were big open spaces between the bundles. They were darker than the rest of sample area, but the darker colour did not result from the colour of fibres, rather it was caused by an insufficient lightening of the space being partially inside the sample. Therefore, generally, the area completely covered by fibres was selected carefully for the colour measurement.

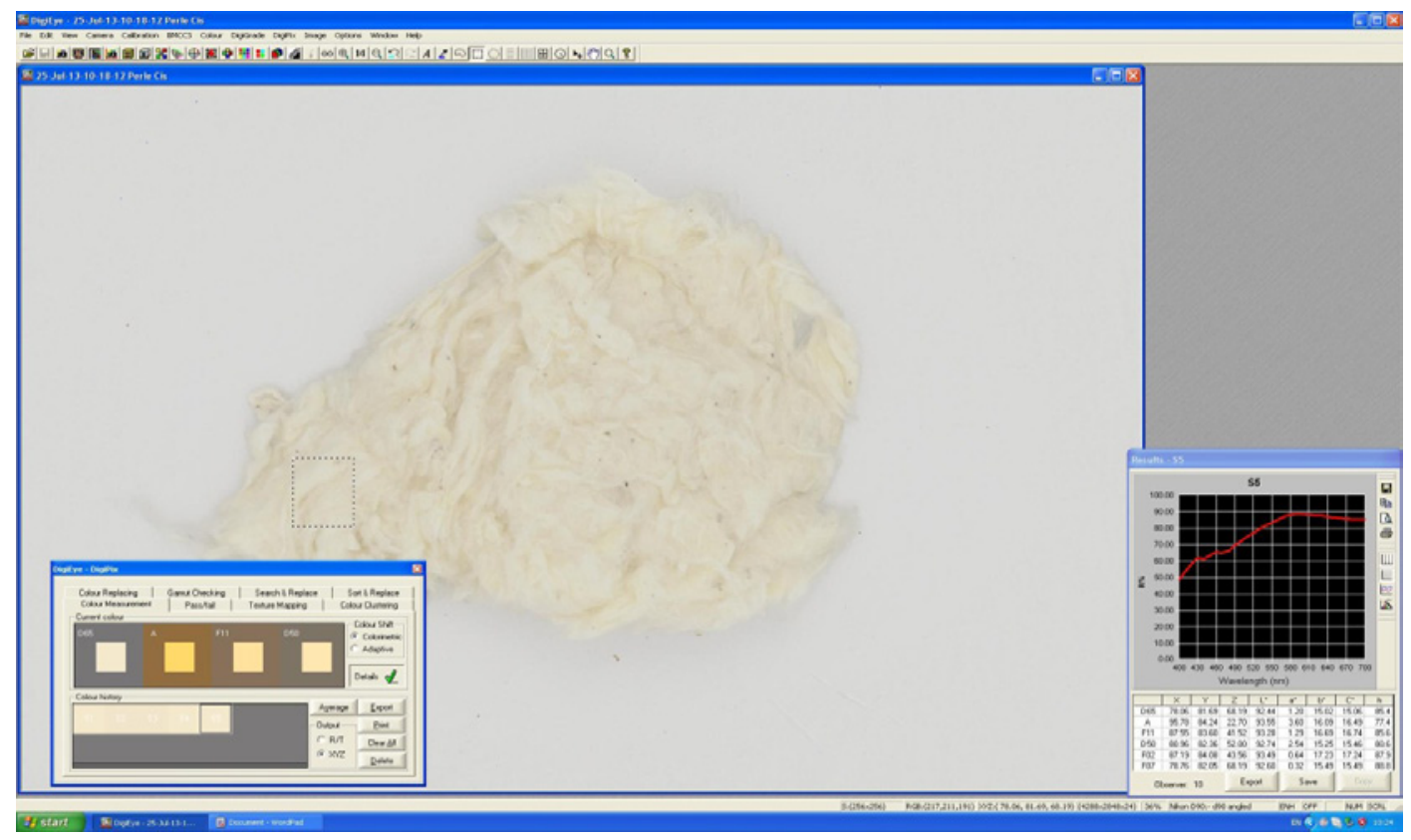

Figure 1. Colour measurement of small rectangular area of cotton sample.

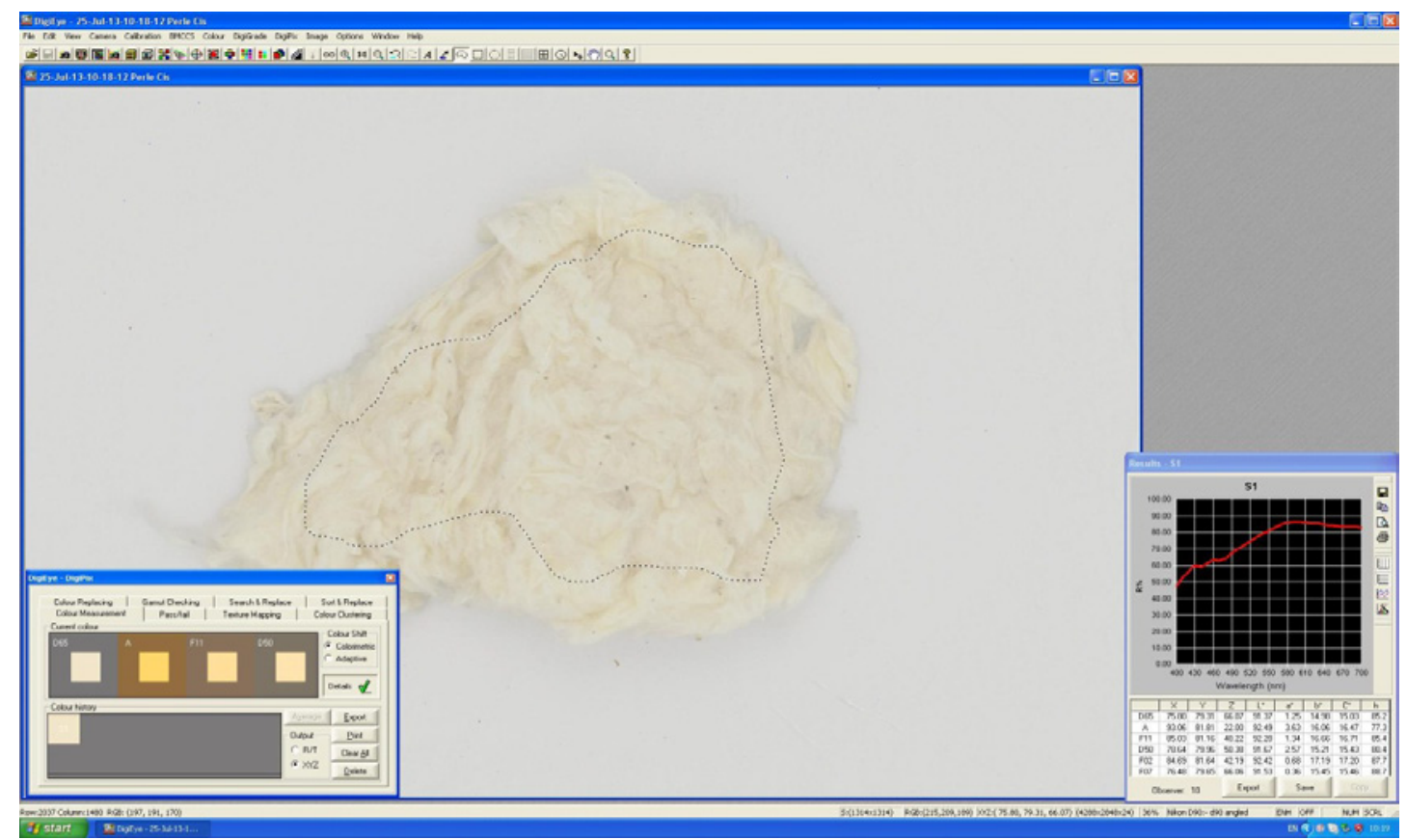

Figure 2. Colour measurement of irregular shape covering a majority of cotton sample area. 
In the second part of the investigation, the choice of the sample image area for the colour measurement by the DigiEye was performed using the procedure selected on the basis of the results obtained in the first part of the investigation.

Colour measurement by means of the HVI 900 was performed according to the procedure elaborated in the Polish Standard PN-P-04693:1998P. In the colour measurement process, cotton was placed in the sample window and compressed to a predetermined pressure. The light was reflected from the surface of the cotton sample through two proprietary interference filters. These filters were wide band interference filters - one located in the blue region of the spectrum and the other located in the green region of the spectrum - chosen to approximate $\mathrm{CIE}$ standard observer functions. The light was measured by two separate detectors. The signals from these detectors were used to calculate the sample colour characteristics: the $\mathrm{Rd}$ and $+b$ [12].

\subsection{Results and discussion}

Results of measurement of colour parameters by means of the DigiEye are presented in Table 1. Table 1 contains results obtained with the illuminant D65.

The next part of the investigation discusses the chosen parameters that have been applied in the former investigations $[3,13,16]$ for the colour assessment of cotton raw materials, such as Rd, lightness and colour coordinates $a^{*}$ and $b^{*}$. Investigations confirmed that the lightness is strongly correlated with the Rd measured by the HVI and it can be applied in cotton classification [12]. Similarly, the colour coordinate $b^{*}$ is correlated with the $+b$ measured by the HVI. There are also expectations to apply the spectrophotometer CIE L*a* ${ }^{*}{ }^{*}$ data in the cotton colour assessment [15].

Figure 3. presents a comparison of spectral $\mathrm{R}$ curves for the cotton sample CO 1.

The Rd curves for the small rectangular areas $S 1-\mathrm{S} 5$ are very similar. The curve representing an average spectral $R$ has a course similar to the curve representing the spectral $R$ measured for the irregular shape covering the majority of the sample area. However, the values of $\mathrm{R}$ measured for the big measured area are lower than the appropriate average values and values obtained for particular small rectangular areas. Similar relationships have been stated for all measured cotton samples. It results from the fact that the bigger irregular shape contains darker areas insufficiently lightened (Figure 2). It causes the average $\mathrm{Rd}$ and lightness measured for the big area covering the majority of measured samples in all cases to be lower than the average values of these parameters calculated on the basis of the results for small rectangular shapes.

Figure 4 presents the spectral $\mathrm{R}$ of the cotton sample CO 4 . In this case, much bigger differences are observed between the spectral Rd of particular sample areas: S $1-\mathrm{S} 5$. On the other hand, an average spectral $R$ is very close to the $R d$ measured for the big irregular area of the cotton sample, and in the range of wavelength $600-700 \mathrm{~nm}$, both curves are identical.

Table 1. Results of measurement of colour parameters by means of the DigiEye with the illuminant D65.

\begin{tabular}{|c|c|c|c|c|c|c|c|c|c|c|}
\hline $\begin{array}{l}\text { Cotton } \\
\text { variant }\end{array}$ & Parameter & $\begin{array}{l}\mathbf{R} \\
\%\end{array}$ & $x$ & $\mathbf{Y}$ & $\mathbf{Z}$ & $L^{*}$ & $a^{*}$ & $\mathbf{b}^{*}$ & $C^{*}$ & h \\
\hline \multirow{3}{*}{ CO 1} & Aver. & 77.10 & 75.73 & 79.17 & 67.94 & 91.31 & 1.36 & 13.29 & 13.35 & 84.20 \\
\hline & SD & 1.35 & 1.24 & 1.59 & 1.88 & 0.72 & 0.65 & 0.42 & 0.46 & 2.66 \\
\hline & $S$ & 75.25 & 73.65 & 76.91 & 65.53 & 90.28 & 1.51 & 13.56 & 13.64 & 83.60 \\
\hline \multirow{3}{*}{$\mathrm{CO} 2$} & Aver. & 73.46 & 74.13 & 77.04 & 65.29 & 90.34 & 2.26 & 13.86 & 14.05 & 80.70 \\
\hline & SD & 1.59 & 1.79 & 1.89 & 1.42 & 0.87 & 0.67 & 1.04 & 1.11 & 2.26 \\
\hline & $S$ & 72.25 & 73.21 & 76.17 & 63.11 & 89.94 & 2.08 & 15.08 & 15.22 & 82.20 \\
\hline \multirow{3}{*}{$\mathrm{CO} 3$} & Aver. & 76.62 & 74.82 & 78.04 & 68.17 & 90.80 & 1.72 & 12.20 & 12.32 & 82.00 \\
\hline & SD & 2.64 & 2.69 & 2.84 & 2.58 & 1.30 & 0.10 & 0.49 & 0.48 & 0.80 \\
\hline & $S$ & 72.44 & 72.62 & 75.71 & 66.04 & 89.73 & 1.76 & 12.16 & 12.29 & 81.80 \\
\hline \multirow{3}{*}{$\mathrm{CO} 4$} & Aver. & 72.17 & 72.74 & 75.90 & 64.45 & 89.81 & 1.65 & 13.69 & 13.79 & 83.10 \\
\hline & SD & 2.79 & 2.61 & 3.00 & 3.61 & 1.40 & 0.61 & 1.07 & 1.09 & 2.38 \\
\hline & $S$ & 71.57 & 72.18 & 74.98 & 63.61 & 89.38 & 2.32 & 13.69 & 13.88 & 80.40 \\
\hline \multirow{3}{*}{ CO 5} & Aver. & 77.87 & 78.67 & 81.52 & 69.15 & 92.36 & 2.75 & 14.07 & 14.34 & 78.90 \\
\hline & SD & 1.71 & 1.89 & 2.02 & 1.44 & 0.89 & 0.38 & 0.96 & 0.96 & 1.50 \\
\hline & $S$ & 75.23 & 75.98 & 78.54 & 66.61 & 91.02 & 3.11 & 13.91 & 14.26 & 77.40 \\
\hline
\end{tabular}

Legend: $\mathrm{R}$ - average reflectance calculated as an arithmetic mean from reflectance of waves of particular length, Aver. - arithmetic mean from results for five small rectangular areas, SD - standard deviation of the results for five small rectangular areas, $S$ - result of measurement of the big area of irregular shape covering a majority of sample area. 


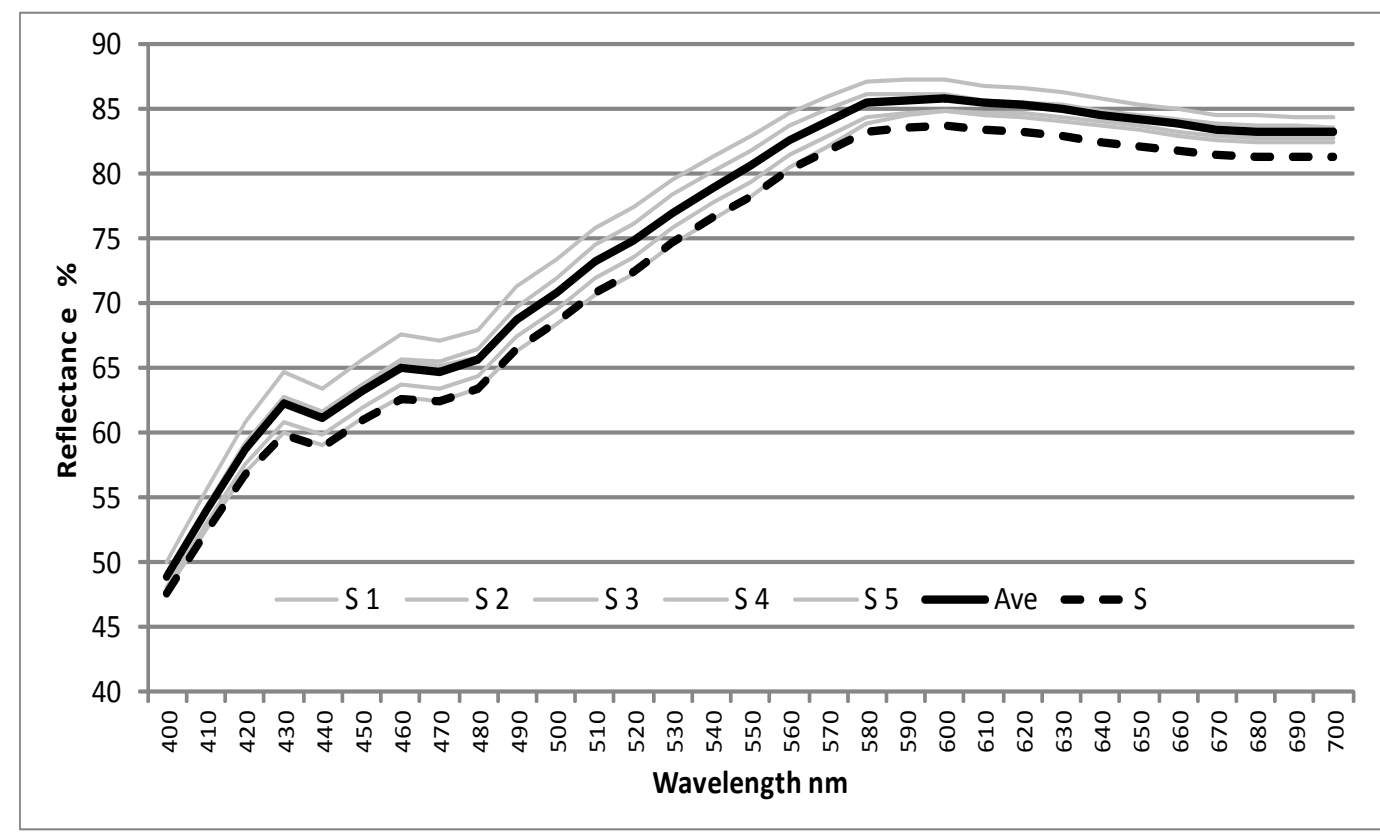

Figure 3. Spectral reflectance of the cotton sample CO 1.

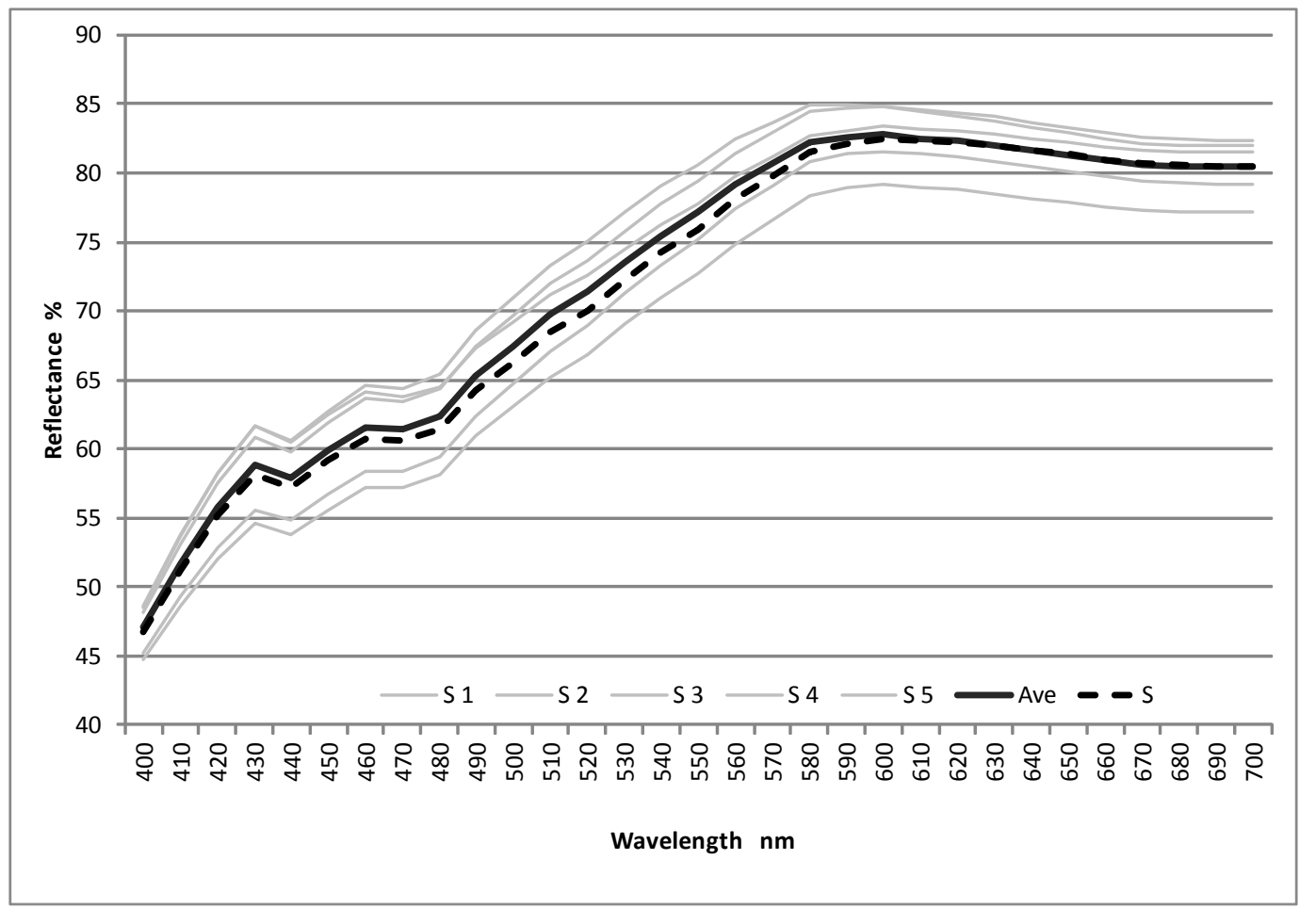

Figure 4. Spectral reflectance of the cotton sample $\mathrm{CO} 4$

Figure 5 presents the comparison of lightness measured for small rectangular shapes and big irregular shape. Lightness for the big irregular area is a little lower than the average lightness calculated on the basis of the results for five small rectangular areas. Moreover, in the case of the sample CO 1, the lightness of big area is lower than the lightness of particular small rectangular areas. We can also see that differentiation of the lightness results is slight.

The biggest differentiation of lightness has been stated for the samples CO 3 and $\mathrm{CO} 4$. In the case of the sample $\mathrm{CO} 4$, the lightness measured for big irregular shape is very close to the average lightness calculated on the basis of the results for five small rectangular areas; additionally, the lightness of small rectangular areas S 4 and $S 5$ is lower than the lightness of big area of irregular shape (Figure 6).

An average value of the colour coordinate $b^{*}$ calculated on the basis of the results for five small rectangular areas is at the same level as the value measured for the big irregular area of sample (Table 1). Only in the case of cotton sample $\mathrm{CO} 2$, the value of the $\mathrm{b}^{*}$ coordinate measured for the big 
irregular area is significantly higher than the average value. Differentiation of the colour coordinate $b^{*}$ between the particular small areas of cotton sample $\mathrm{CO} 1$ is presented in Figure 7. We can see that the value of coordinate $b^{*}$ of particular small rectangular areas is in the range from 12.78 to 13.73. Much bigger differentiation (from 12.18 to 15.05 ) of the colour coordinate $b^{*}$ has been observed in the case of the sample CO 4 (Figure 8 ), but in this case, the average value of the coordinate $b^{*}$ is identical to the value obtained for the big irregular area of sample.

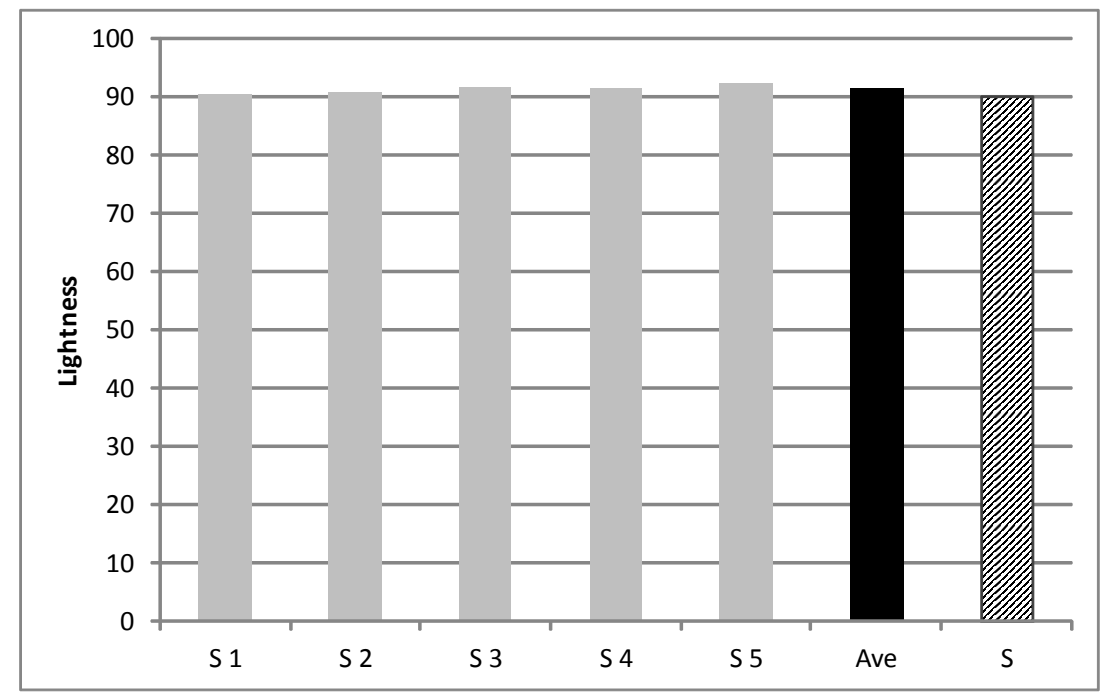

Figure 5. Lightness of the cotton sample CO 1.

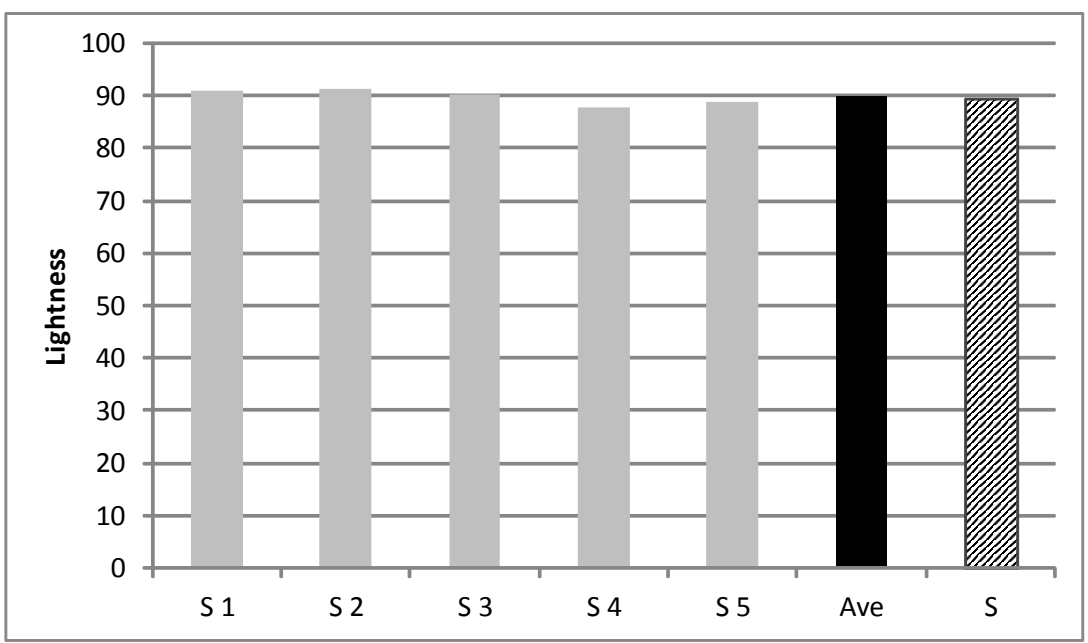

Figure 6. Lightness of the cotton sample $\mathrm{CO} 4$.

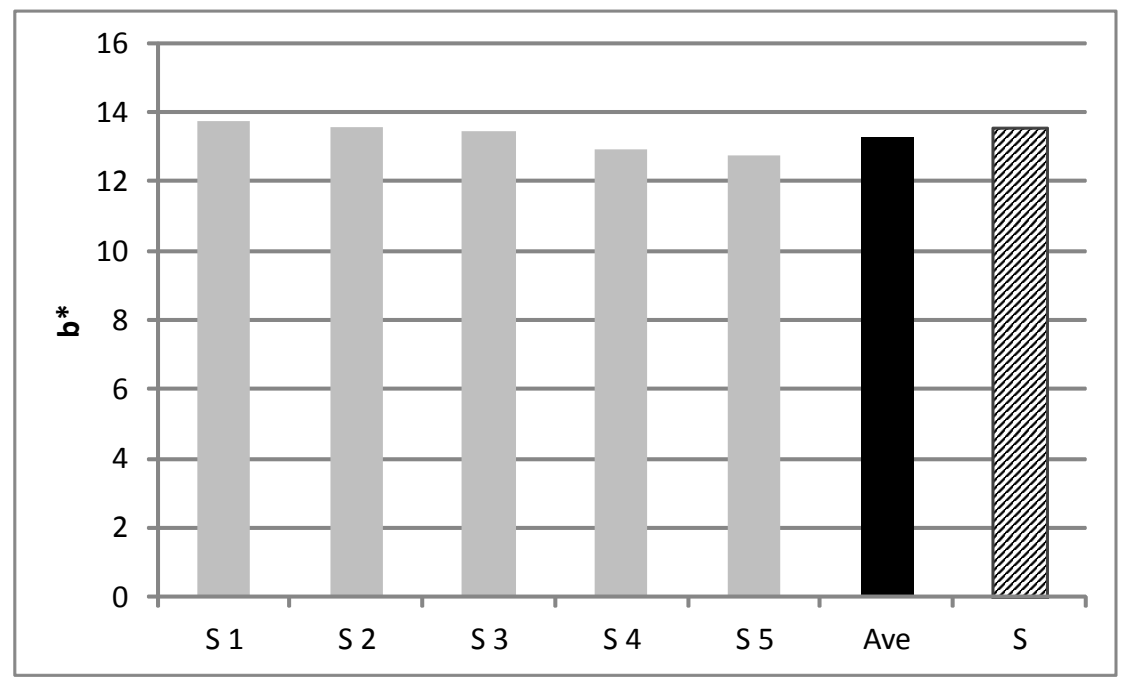

Figure 7. Colour coordinate $b^{\star}$ for the cotton sample CO 1. 
Figures 9 and 10 present the values of the colour coordinate $a^{*}$ of cotton samples CO 1 and $\mathrm{CO} 3$. In the case of the sample CO 1 , we can observe a significant differentiation of the $a^{*}$ coordinate value measured for particular small rectangular areas, whereas for the sample $\mathrm{CO} 3$, the differentiation of the colour coordinate $\mathrm{a}^{*}$ is much lower. Only the result for the area $\mathrm{S} 2$ differs significantly from the rest of results obtained for the sample CO 3.

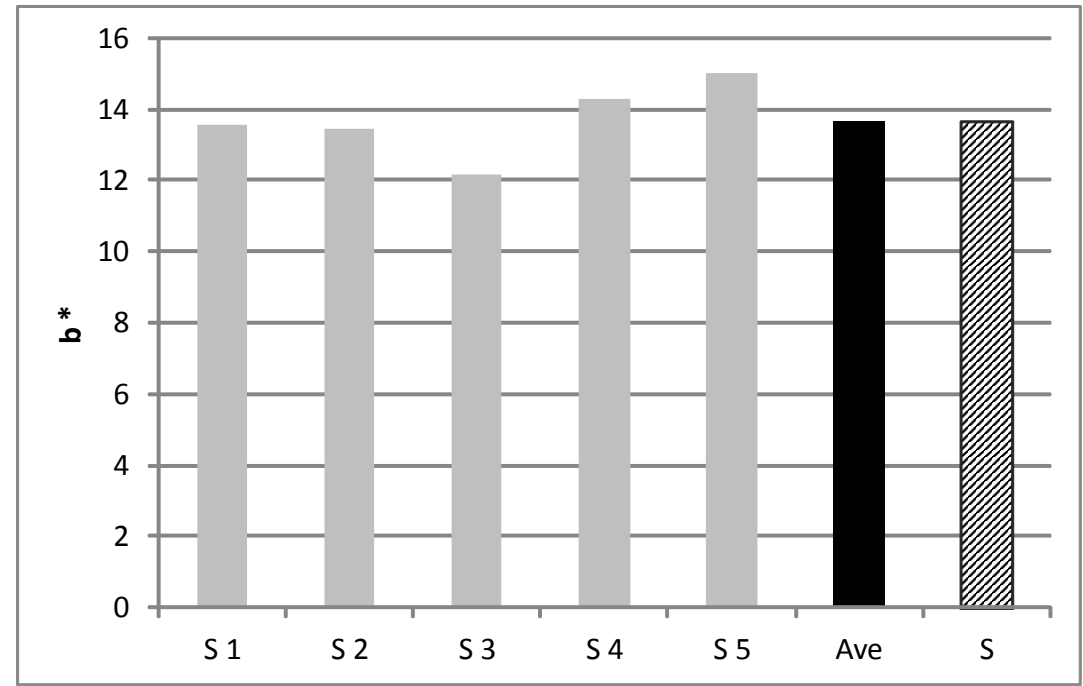

Figure 8. Colour coordinate $b^{*}$ for the cotton sample CO 4.

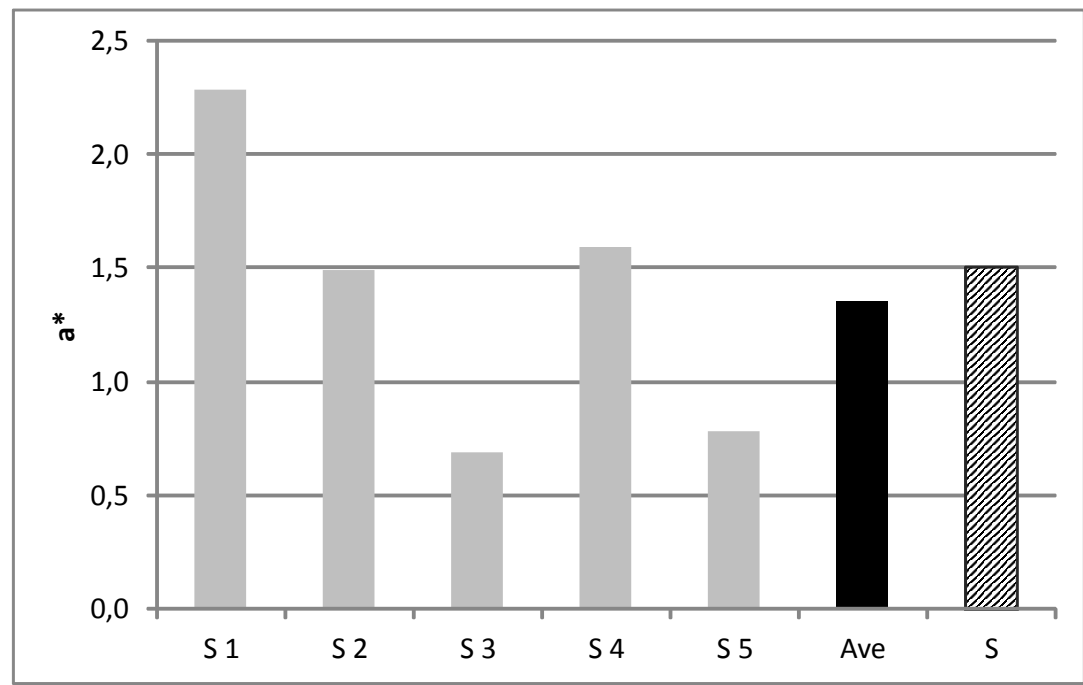

Figure 9. Colour coordinate $\mathrm{a}^{\star}$ for the cotton sample CO 1.

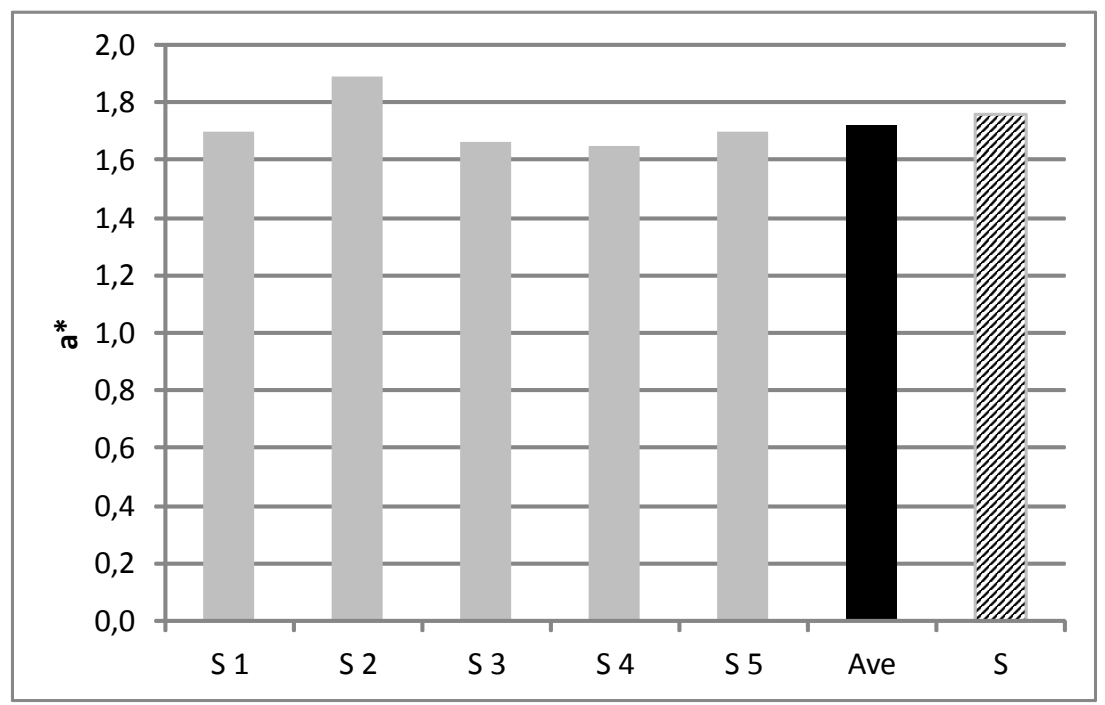

Figure 10. Colour coordinate $a^{*}$ for the cotton sample $\mathrm{CO} 3$. 
Statistical analysis using t-Student test confirmed that in a majority of cases, the differences between the average value of colour parameters $L^{*}, a^{*}, b^{*}$ from the results obtained for five small rectangular areas and value of these parameters for the big irregular area covering a majority of sample image surface are statistically insignificant at the probability level 0.95 . In some cases, the value of the $t$ variable is between the values of the $\mathrm{t}$-Student variable at the probability level 0.95 and 0.99 . In this case, we should assume that there is statistical difference between the analysed values; nevertheless, it should be confirmed by further investigations. Only in two cases $\left(L^{*}\right.$ for sample $\mathrm{CO} 1$ and $\mathrm{CO} 5$ ), it was stated that difference between the average value of the lightness and value determined for the big irregular area is statistically significant.

The results of colour measurement by means of the DigiEye have been compared with the results from the HVI. Figure 11 presents the comparison of an average $R$ from the DigiEye and Rd from the HVI. On the basis of the presented data, it can be stated that the results from the DigiEye and $\mathrm{HVI}$ are at the same level. In the case of the colour coordinate $b^{*}$ from the DigiEye and $+b$ from the HVI, the differences are more significant (Figure 12). They can result from the way of sample preparation for measurement. While measuring the colour by the $\mathrm{HVI}$, the cotton sample is compressed to a predetermined pressure. This pressure is necessary to avoid the influence in the way of sample preparation on the measurement results [12]. Sample area measured by the HVI closely adjoins the glass that ensures even lightening of measured surface. In the case of measurement by means of the DigiEye, it was the first such trial to assess the colour of cotton raw material by this method. Samples for the measurement were not specifically prepared. Measurement was done for cotton samples taken directly from cotton bales. The 3D shape of measured cotton sample and uneven arrangement of fibres caused uneven lightening of sample, which influences the results.

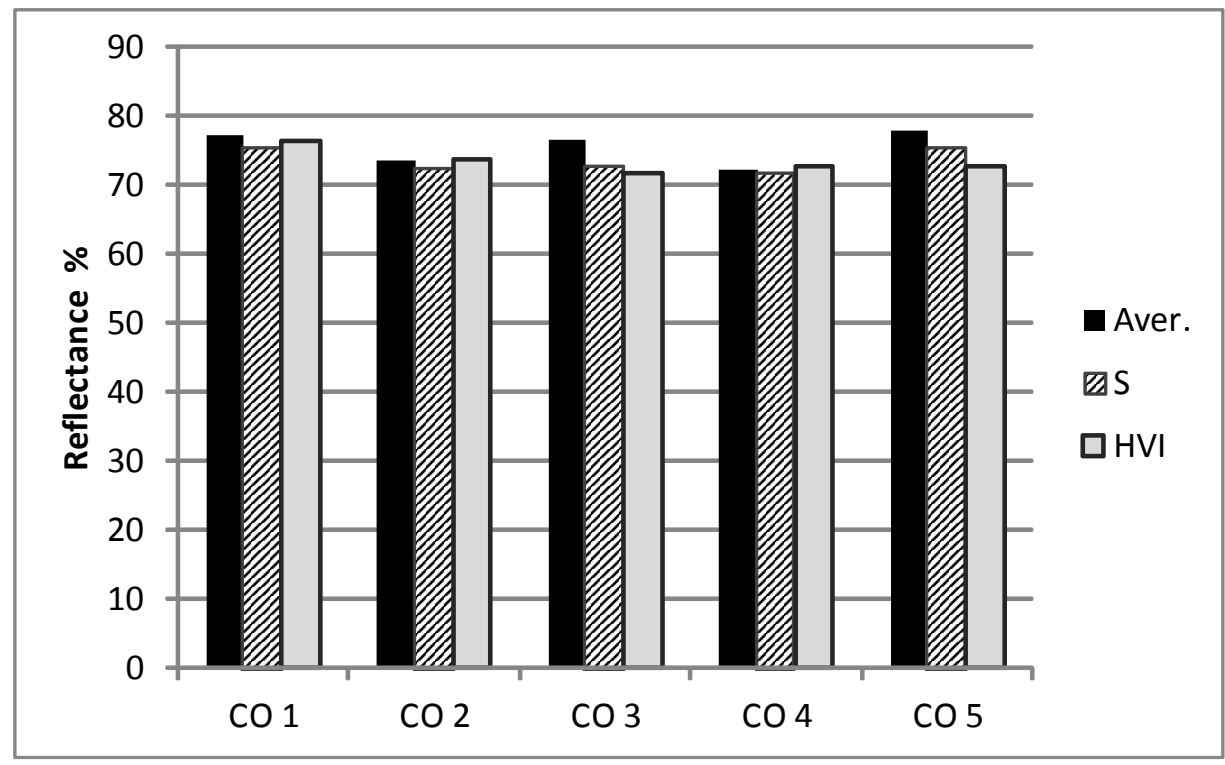

Figure 11. Comparison of reflectance from the DigiEye and HVI.

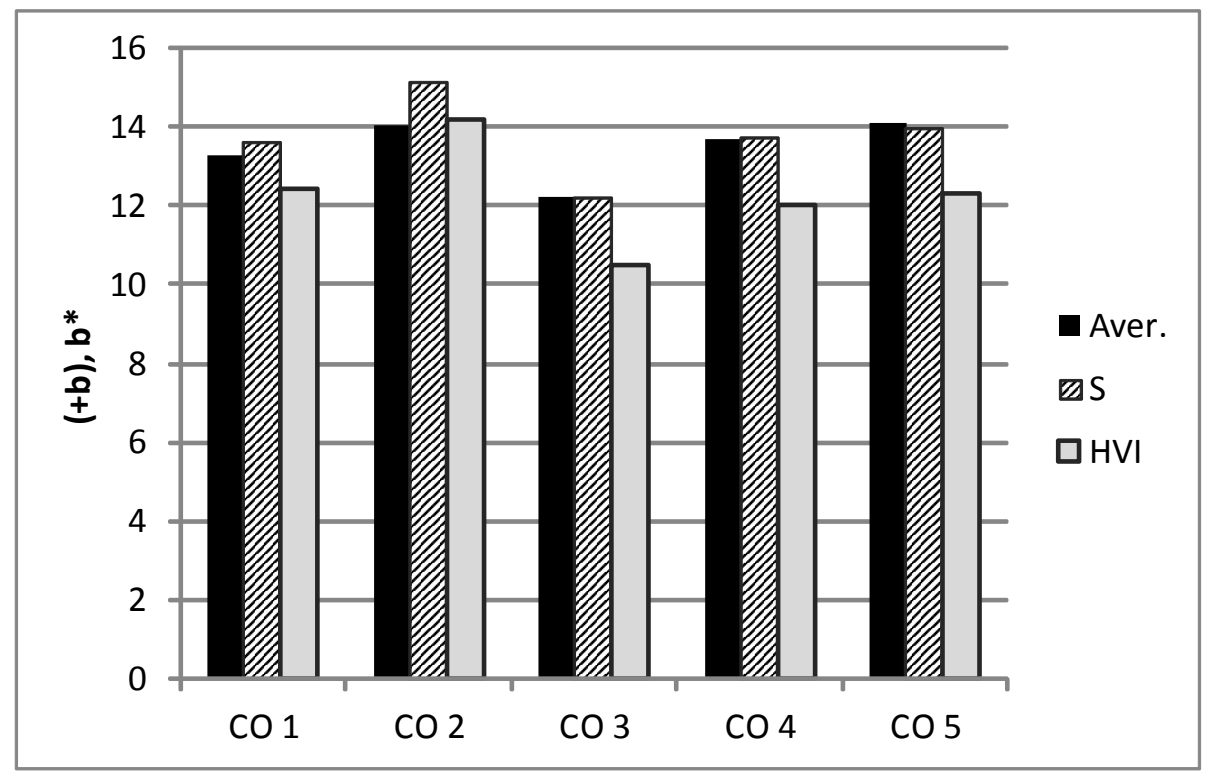

Figure 12. Comparison of colour coordinate $b^{*}$ from the DigiEye and yellowness $(+b)$ from the HVI. 
Obtained results allow to assume that both methods of choice of sample image area for the colour measurement seems to be equivalent from the point of view of the agreement with the results from the HVI. Due to this fact, the second method of choice of one big area covering the majority of the sample image has been applied for further investigation, because in this method, the measured area of the investigated cotton sample is similar to the area measured by means of the HVI.

The aim of the second part of the investigation was to assess a correlation between the results from the DigiEye and HVI. In order to do this, 21 cottons of different origin were measured by means of both instruments. While choosing the image area for the colour measurement, the places insufficiently lightened were carefully avoided in order to eliminate the influence of cotton preparation and fibre arrangement on colour results.

The relationships between the results from the DigiEye and $\mathrm{HVI}$ are presented in Figures 13 and 14.
Statistical analysis confirmed that there is strong and statistically significant correlation between the reflectance from the DigiEye and $\mathrm{HVI}\left(\mathrm{R}_{\mathrm{x}, \mathrm{y}}=0.856\right)$. It was also stated that the values of the reflectance from both instruments are at the same level.

There is also correlation between the colour coordinate $b^{*}$ from the DigiEye and the $+b$ from the HVI, but the value of the correlation coefficient $\left(\left(R_{x, y}=0.694\right)\right.$ is lower than in the case of the $R d$.

At this stage of investigations, there were no data to elaborate the procedures of sample preparation. Due to this fact, the results should be considered as preliminary and they could be the base for further investigations aimed at application of the DigiEye in measurement of colour of cotton raw materials. First of all, it is necessary to prepare the cotton sample in a way that ensures even lightening of measured surface. Next, it is also necessary to perform the colour measurement of bigger number of cotton samples in order to assess a correlation between the results from the DigiEye and HVI.

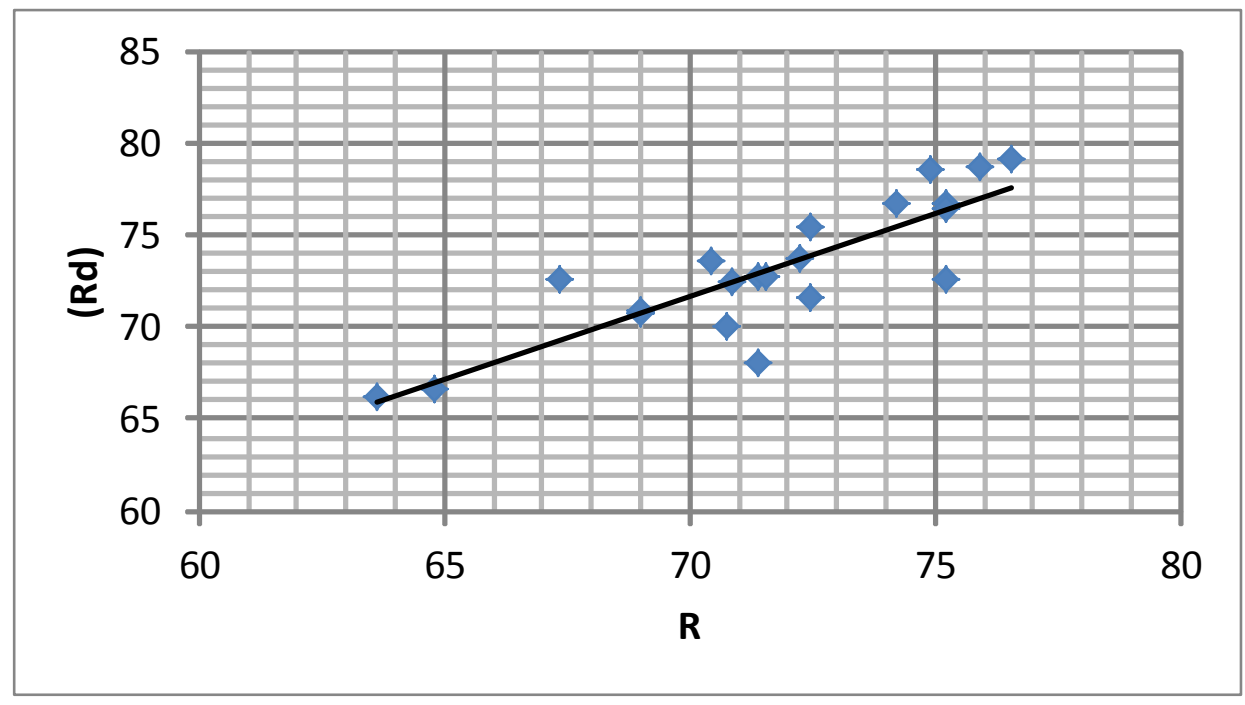

Figure 13. Relationship between the R from the DigiEye and the Rd from the HVI.

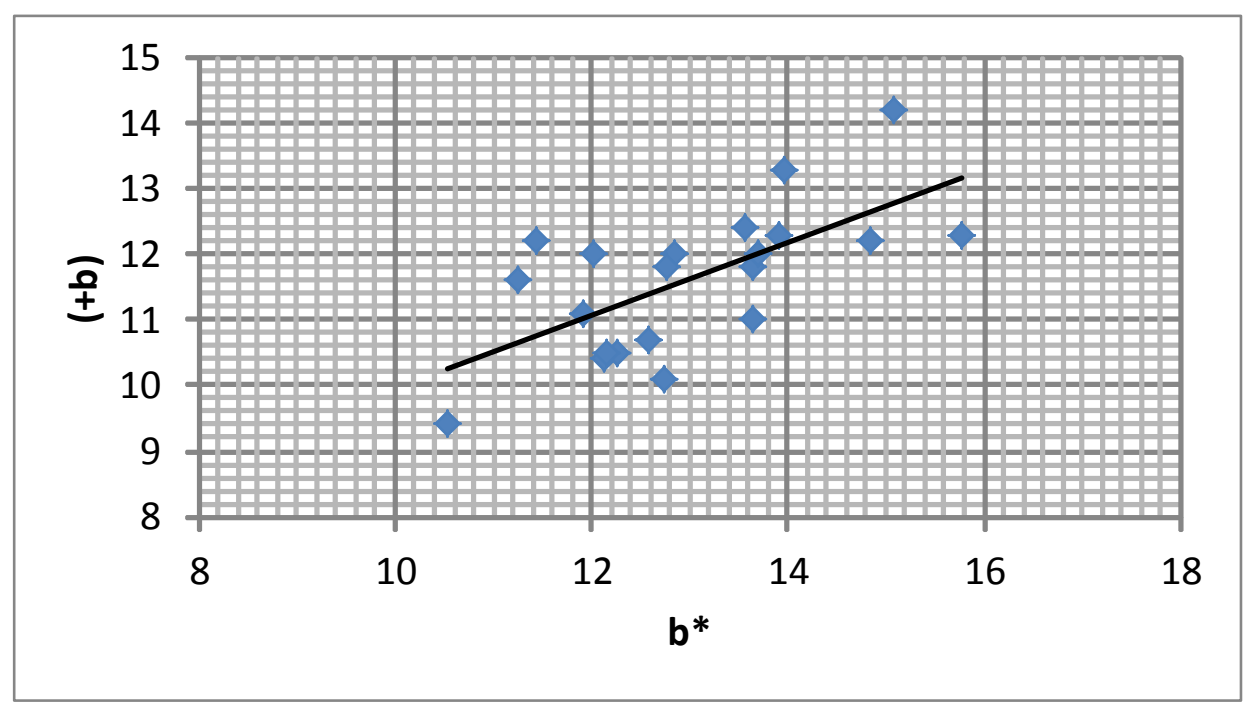

Figure 14. Relationship between the colour coordinate $b^{*}$ from the DigiEye and the yellowness from the HVI. 


\section{Conclusions}

On the basis of the investigations carried out, it can be stated that the DigiEye can be applied in the cotton colour measurement. It provides colour results in the commonly recognized $\mathrm{CIE} \mathrm{L}^{*} \mathrm{a}^{*} \mathrm{~b}^{*}$ colour space.

Presented results show that there is an agreement between the reflectance from the DigiEye and HVI. However, there are visible differences between the colour coordinate $b^{*}$ from the DigiEye and $+b$ from the HVI. Stated differences can result from the way of sample preparation and way of choice of pixels for the colour measurement by means of the DigiEye.

Obtained results allow to assume that both methods of choice of sample image area for the colour measurement seem to be equivalent from the point of view of the agreement with the results from the HVI. Due to this fact, the second method of the choice of one big area covering the majority of sample image should be recommended for the future implementation, because this method takes much less time, and additionally, the measured area of the investigated cotton sample is similar to the area measured by means of the HVI.

Presented results should be considered as preliminary. They can be a starting point for further investigations aimed at elaboration of method of cotton colour measurement and cotton classification into the colour grades on the basis of the data from the DigiEye.

\section{Acknowledgement}

This work is (partially) supported by Structural Founds in the frame of the project titled "Development of research infrastructure of innovative techniques and technologies of textile clothing industry" CLO - 2IN - TEX, financed by Operational Programme Innovative Economy, 2007-2013," Action 2.1.

\section{References}

[1] Adamczyk P., Rutowicz J., Frydrych I., Comparative Analysis of Results Obtained from Devices: Macbeth \& DigiEye, International Conference STRUTEX'2012, Liberec Czech Republic, 2012.

[2] Aspland J. R., Williams S. A., The Effect of Cotton Grade on the Colour Yield of Dyed Goods, Textile Chem. Colour 23 (2), 1999, pp. 23 - 25.

[3] Berns S. R., Billmeyer and Saltzman's principles of colour technology ( $3^{\text {rd }}$ edition) New York, 2000, A Wiley Interscience.

[4] Buriyev R. A., Ustyugin V.E., Production, Classification and Certification of Cotton in Uzbekistan, 24 ${ }^{\text {th }}$ International Cotton Conference, Bremen 1998.
[5] Cheng L., Ghorashi H., Duckett K., Zapletalova T. Watson M.D., Colour Grading of Cotton. Part II: Colour Grading with an Expert System and Neural Networks, Textile Research Journal 69 (12), 1999, pp. 893 - 903.

[6] DigiEye User Guide Version 2.51, VeriVide Ltd., 2010.

[7] Duckett K., Zapletalova T., Cheng L., Ghorashi H., Watson M. D. Colour Grading of Cotton. Part I: Spectral and Colour Image Analysis, Textile Research Journal 69 (11), 1999, pp. $878-886$.

[8] Frydrych I., Matusiak M., Characteristics of Medium Staple Cottons of Central Asia Origin, 25 ${ }^{\text {th }}$ International Cotton Conference, Bremen 2000.

[9] Frydrych I., Matusiak M., Challenges For Fiber Quality Measurement, Presented at Technical Seminar at the $61^{\text {st }}$ Plenary meeting of the International Cotton Advisory Committee, Cairo, Egypt, 2002, pp. 17 - 27.

[10] Ibrahim, Abbas E.I., Effect of Cotton Cultivar and Seed Grid Adjustment on Ginning Efficiency and Fiber Properties, Journal of Applied Sciences Research, 6(11), 2010, pp. 1589 - 1595.

[11] Knowlton J. L. Improving Cotton Colour Classification. http://www.cottoninc.com/2004ConferencePresentations/ ImprovingHVIColourGrade/.

[12] Matusiak M., Walawska A., Measurement of Colour of Cotton Fibres by Means of Spectrophotometer, $6^{\text {th }}$ International Conference TEXSCIE'2007, Liberec 2007.

[13] Matusiak M., Walawska A., Important Aspects of Cotton Colour Measurement, Fibres \& Textiles in Eastern Europe 2010, Vol. 18, No. 3 (80), pp. $17-23$.

[14] Mor U., Multifunction Fiber Quality Testers (FQT) the New Generation \& Technology for More Complete Cotton Quality Information, http://lintronics.com.

[15] Rodgers J., Thibodeaux D., Cui X., Martin V., Watson $M$. , Investigations of the Impacts of Instrumental and Operational Variables on Colour Measurement, World Cotton Research Conference WCRC -4, Lubbock 2007.

[16]Rutkowski J., Examination of Physical-Mechanical Parameters of Carded and Combed Yarns Produced from Biological Cotton, Fibres \& Textiles in Eastern Europe April/June 2008, Vol. 16, No. 2(67) 2008.

[17] Shofner F., Watson M., Zhang Y., Lee S., Shofner K., Moving to CIE Colour, Traceably! 2006 Beltwide Cotton Conferences, San Antonio 2006.

[18] Uster@ HVISpectrum - What does the data mean?, 2004.

[19] Xu B., Fang C., Huang R., Watson M.D, Chromatic Image Analysis for Cotton Trash and Colour Measurements, Textile Research Journal 67(12), 1997, pp. 881-890.

[20] Xu B., Fang C., Huang R., Watson M. D, Cotton Colour Measurement by an Imaging Colourimeter, Textile Research Journal 68 (5), 1998, pp. 359 - 370.

[21] Xu B., Su J., Dale D. S. Watson M. D., Cotton Colour Grading with Neural Network, Textile Research Journal 70 (5), 2000, pp. 430 - 436.

[22] Yaoyuneyong G., Effects of Illuminants and Retail Environments on Colour of Textile Fabrics, Ph.D. thesis, College of Human Sciences of The Florida State University, 2007. 